\title{
El circuito monetario: los bienes de capital y de las instituciones financieras no bancarias. Evidencia en la economía mexicana The monetary circuit: capital goods and non-banking financial institutions. Evidence in the Mexican economy
}

Journal of Economic Literature (JEL): E22, E44, E52, E63

Palabras clave:

Circuito Monetario

Créditos y financiamiento no bancario

Países en desarrollo

Keywords:

Monetary Circuit

Credit, Finance

Developing Economies

Fecha de recepción:

17 de enero de 2017

Fecha de aceptación: 14 de agosto de 2017

\section{Resumen}

La teoría del circuito monetario es un marco teórico relevante para explicar la movilización de recursos financieros para la producción y el crecimiento económico, especialmente si se añade de manera explícita la recirculación de las ganancias. En este trabajo se discute de manera crítica la teoría del circuito monetario y se analiza su funcionamiento en entornos de economías en desarrollo. A partir de lo anterior se busca mostrar que los créditos bancarios están correlacionados con la masa salarial, mientras que los gastos de inversión están ligados a los instrumentos financieros no bancarios; resaltándose que en el periodo de financiarización se amplió la profundización financiera sin generar mayores volúmenes de financiamiento.

\section{Abstract}

The monetary circuit theory is a relevant theoretical framework to discuss the mobilization of final resources for production and economic growth, especially if explicitly is included profit recirculation to the economy. In this work is discussed critically the monetary circuit theory and is applied to developing economies. We want to show that bank credits are related to the wage bill, while investment spending is linked to financial non-banking instruments. In addition, we want to show that financial depth although amplified the financial circuit did not increased finance for investment spending or production.

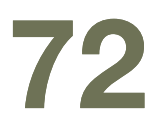

ECONOMíAunam vol. 14, núm. 42, septiembre-diciembre, 2017
(C) 2017 Universidad Nacional Autónoma de México, Facultad de Economía. Este es un artículo Open Access bajo la licencia CC BY-NC-ND (http://creativecommons.org/licenses/by-nc-nd/4.0/). 
Introducción

El desarrollo económico de los países de América Latina se ha sustentado sobre la base de reducidos nive-

les de producción de bienes de capital fijo y sistemas financieros organizados alrededor de los bancos, con débiles instituciones financieras no bancarias, inclusive en el periodo de financiarización. Una de las grandes limitaciones del crecimiento económico ha sido la reducida producción de bienes de capital fijo (Fajnzylber, 1983) y la recirculación parcial de las ganancias al sector productivo (Kaldor, 1959). El resultado de estas dos limitaciones en países en desarrollo es que el sistema financiero debe movilizar altos volúmenes de financiamiento para importar bienes de capital fijo, lo cual puede inducir desequilibrios estructurales y parálisis del sector productivo y financiero.

El objetivo de este trabajo es argumentar que el circuito monetario debe integrar de manera explícita la recirculación de ganancias, que opera como una fuente de liquidez para la realización de la inversión fija, función asumida por instituciones financieras no bancarias especializadas que se encargan de la inter-

Las instituciones financieras no bancarias tienen la función de recolectar las ganancias generadas por la producción que deben transformar en ahorro

financiero y proveen financiamiento de largo plazo; mientras los bancos adelantan financiamiento

para cubrir el capital circulante mediación financiera.

Uno de los argumentos centrales de este análisis es que la teoría del circuito monetario es un marco analítico adecuado para explicar el crecimiento económico porque explícita la relación entre las empresas, las familias y las instituciones financieras bancarias y no bancarias; generándose una discusión sí los bancos requieren financiar el gasto corriente de las empresas o deben adelantar recursos para la compra de los bienes de capital fijo finales. Desde esta perspectiva, se señala que las instituciones financieras no bancarias tienen la función de recolectar las ganancias generadas por la producción que deben transformar en ahorro financiero y proveen financiamiento de largo plazo; mientras los bancos adelantan financiamiento para cubrir el capital circulante.

En esta discusión se diferencia entre el financiamiento a la producción y la inversión y se supone que la banca y las instituciones financieras no bancarias asumen distintas funciones. La banca crea deudas (liquidez) y las instituciones financieras no bancarias intermedian el ingreso no consumido y las ganancias. Ello implica que los bancos tienen un papel importante en el inicio del proceso de producción; determinando su volumen y composición, mientras las instituciones financieras no bancarias estabilizan al proceso de crecimiento (o garantizan su equilibrio, Bossone, 2001: 858).

A partir de lo anterior se puede argumentar, primero, que el financiamiento bancario está ligado a la producción, donde se incluye todos los sectores, inclusive el sector productor de bienes de capital fijo, por consiguiente el financiamiento neto del sector empresarial se limita a cubrir la masa salarial. Se resalta que si el gasto de los asalariados no tiene fugas, regresa al sector empresarial, y anula las deudas bancarias de las empresas. Segundo, lo anterior no invalida los créditos intra-empresariales (por ejemplo para la compra de bienes de capital finales o intermedios o, incluso para el comercio de títulos financieros -adquisición de títulos financieros no bancarios-, los cuales, empero, se anulan al interior del sector capitalista. Tercero, las fugas en la circulación del gasto de los asalariados y de las ganancias hacia las empresas 
pueden provocar inestabilidad financiera y parálisis económica. Cuarto, éste proceso se complica en los países en desarrollo (latinoamericanos) por la debilidad del sector productor de bienes de capital fijo y de las instituciones financieras no bancarias que movilizan el ahorro hacia el sector empresarial (asalariado y las ganancias capitalistas) que impiden cerrar el circuito monetario.

Con base en lo anterior, el propósito de este trabajo es, por un lado entender la creación de liquidez y su transformación en ingreso (salarios y ahorro) y gasto (demanda de bienes finales) y, por otro, la recirculación de las ganancias que cierran el circuito monetario al proveer liquidez para la venta de los bienes de capital terminados.

Los anteriores planteamientos son considerados como los elementos centrales del circuito monetario, lo cuales, se discuten en entornos de los países en desarrollo. Para lograr estos objetivos se divide este trabajo en cuatro secciones, en la segunda, después de esta introducción, se expone de manera crítica el modelo del circuito monetario, donde se problematiza la relación entre el sector financiero, las empresas y las familias, al tomar en cuenta la correlación de fuerzas de cada sector, lo cual determina el monto y la composición de la producción, así como la distribución de las ganancias. En la tercera sección se analiza la creación y destrucción de dinero y la recirculación de las ganancias en los países en desarrollo en el periodo de financiarización, aplicado a la economía mexicana, donde dominan instituciones financieras privadas, con reducida intervención gubernamental en la movilización de recursos. Finalmente, en la cuarta sección, se presentan las conclusiones.

Una revisión crítica de la teoría del circuito monetario
La teoría del circuito monetario se entiende mejor en contextos de economías ca-

pitalistas puramente monetarias, dominadas por deudas privadas, las cuales circulan bajo la forma de depósitos bancarios privados, definidos como símbolos de valor, desligados de mercancías, aunque representan valor. Estas deudas simbolizan valor y tiene la capacidad de realizar todas las funciones del dinero, incluido la realización de pagos finales (Graziani, 1984 y 2003).

Las relaciones principales de los sistemas capitalistas tienen lugar entre empresas, hogares y sector financiero. El sector empresarial se subdivide entre los productores de bienes de consumo y de capital; se distinguen por contratar fuerza de trabajo, que combinados con acervo de capital existentes, generan producción. El objetivo de las empresas es apropiarse de ganancias, las cuales se reparten entre los diversos subsectores capitalistas (empresarios y dueños de capital). Por su parte, los hogares están constituidos por agentes que perciben ingresos por la venta de su fuerza de trabajo y pueden apropiarse de ganancias a través del comercio con títulos financieros. El ingreso se destina a la demanda de bienes de consumo y al ahorro, éste último puede adquirir la forma de depósitos bancarios y de títulos financieros. Finalmente, el sector financiero está constituido por la banca y las instituciones financieras no bancarias (IFNB), donde la primera crea liquidez de la nada (ex-nihilo) por los cuales perciben intereses; mientras las IFNB son intermediarios financieros. 
Uno de los supuestos centrales de estas teorías es que las ganancias generadas por la producción deben regresar a las empresas, a través del ahorro financiero o se mantienen como ganancias retenidas en las empresas, la cual -en conjunto-, se destinan a la realización de la inversión, i.e., venta finales de bienes de capital fijo; entonces, la función del ahorro financiero es estabilizar el crecimiento. Específicamente, las IFNB concentran el excedente total de la economía que transforman en fondos de inversión y generan financiamiento de largo plazo y permiten la venta de los bienes de capital fijo, adicionalmente permite saldar los deudas intra-capitalistas (al interior del sector empresarial y entre empresarios y rentistas) y pagar los intereses a la banca. Se señala que una de las funciones centrales del mercado de capitales es otorgar liquidez a los activos no-líquidos.

Un elemento distintivo de este planteamiento es la definición de la tasa de interés. Se asume que es una variable monetaria, determinada por el banco central, que incide sobre el conjunto de la estructura de las tasa de interés. Los bancos

Existen varias versiones del circuito monetario. La más simplificada indica que los bancos proveen liquidez a las empresas solventes vía la emisión de depósitos bancarios que se distinguen por ser ampliamente aceptados por todos los agentes económicos porque cumplen con todas las funciones del dinero comerciales son tomadores de precios (que se determina a partir de la tasa de interés del banco central más un margen, Rochon, 2001) y adelantan liquidez a las empresas, señalándose que son deudas que no consumen ni agotan ningún recurso real (son asientos contables, Keynes, 1937b:209). Por consiguiente, los circuitistas caracterizan a los intereses bancarios como renta pura, porque la banca se apropia de ganancias sin ofrecer a cambio ningún recurso real (Graziani, 2003, Bellofiore y Seccareccia, 1999).

La única vía para que dichas rentas recirculen a las empresas es que las ganancias bancarias ${ }^{1}$ se canalizan a la compra de títulos financieros no bancarios y se convierten en financiamiento de largo plazo para las empresas, o que los bancos paguen intereses similares por los depósitos bancarias de las familias (Bossone, 2001) o recirculen los intereses y las comisiones bajo la forma de sueldos y salarios a los empleados del sector bancario (Seccareccia, 2012-2013). Los intereses de largo plazo, relacionados con los instrumentos financieros no bancarios se consideran como costos para las empresas, porque acceden a recursos reales (ahorros) del conjunto de la economía, que utilizan como financiamiento de largo plazo para la adquisición de bienes de capital fijo. Entonces, las ganancias se transforman en ahorro financiero y se convierte en financiamiento de largo plazo que cierra el circuito monetario. A partir de lo anterior se destaca que los intereses por los préstamos bancarios son una extracción de excedente desde el sector productivo al financiero, mientras que los rendimientos que pagan por los instrumentos financieros no bancarios se catalogan como un costo de producción (Graziani, 2003 y Bossone, 2001, 2003).

Existen varias versiones del circuito monetario. La versión más simplificada indica que los bancos proveen liquidez a las empresas solventes vía la emisión de pasivos contra sí mismos (depósitos bancarios) que se distinguen por ser ampliamente aceptados por todos los agentes económicos porque cumplen con todas las funciones

1 Las ganancias bancarias están definidas por la diferencia entre tasas de interés activa y pasiva, más las comisiones. 
del dinero. La demanda de créditos determina la oferta de dinero, que se distingue por ser infinitamente elástica (Moore, 1988), a partir de lo cual se señala que el dinero es estructuralmente endógeno y no neutro. En este esquema la tasa de interés es una variable distributiva, determinada por el banco central (Moore, 1988) y la banca comercial es tomadora de precio en la fijación del precio de los créditos, añadiendo un margen de ganancia (Rochon, 2001).

Las empresas se relacionan con las familias contratando fuerza de trabajo, cuyos salarios son financiados por los créditos bancarios. ${ }^{2}$ Este proceso tiene lugar al inicio de cada ciclo productivo, cuyo resultado es la producción y la generación de ingresos. La siguiente fase, ocurre cuando las familias recirculan su ingreso hacia las empresas, vía el consumo de bienes y servicios, resaltándose que pueden ahorrar. Si estos ahorros se canalizan a la compra de instrumentos financieros no bancarios regresan a las empresas; empero, si se convierten en depósitos bancarios, las empresas deberán endeudarse para saldar sus cuentas y pagar intereses, aunque los bancos están en posibilidades de equilibrar sus hojas de balances. Las principales fuentes de desequilibrio de este sistema son las variaciones de la tasa de interés por parte del banco central y la microincertidumbre que puede causar interrupciones en la producción (Rochon, 2006)

El circuito monetario consta de dos fases: en la primera (eflux) intervienen las empresas y la banca comercial que acomoda los créditos de los agentes solventes. El banco central tiene la función de acomodar las reservas necesarias a la banca comercial para equilibrar sus hojas de balance y, adicionalmente, asume la función de caja de compensación entre los bancos (Rochon y Rossi, 2004), así como de prestamista de última instancia, y determina la tasa de interés. Las empresas destinan los créditos a la contratación de la fuerza de trabajo, con base en lo cual

Una versión más compleja diferencia entre la creación de créditos para cubrir

la masa salarial y el financiamiento de largo plazo que proviene de los fondos de inversión que otorga liquidez a los activos no líquidos, Ios cuales deberían destinarse a la realización de los bienes de capital generan producción e ingreso. En la segunda fase del ciclo monetario (reflux) se anulan las deudas y, este proceso se realiza vía el gasto de las familias en consumo y el ahorro de este sector que, en conjunto regresa a las empresas, y anula los créditos bancarios.

En este esquema, la demanda efectiva debe ser proporcional al volumen de los créditos y los bancos deben tener expectativas similares a las empresas (Graziani, 2003); además se supone que todos las empresas solventes (independientemente de sus tamaño) enfrentan tasas de interés iguales y no tienen restricciones de liquidez si son empresas solventes, (Graziani 2003). Una discusión ausente en esta visión es el papel de las IFNB que deben recolectar las ganancias y transformarlas en financiamiento de largo plazo.

2 Hay divergencias en torno a este punto. Graziani (2003) postula que los créditos bancarias se limitan a financiar el capital circulante; mientras Rochon (2005) supone que los créditos financian la producción y la inversión, lo cual puede tomar más de un periodo para destruir las deudas, postulando el traslape de periodos en el proceso de creación y destrucción de deudas; mientras Parguez y Seccareccia (2000) señalan que los bancos adelantan liquidez para ambo sectores siempre y cuando que las ganancias sean monetizadas. 
Una versión más compleja de la teoría del circuito monetario 3 diferencia entre la creación de créditos para cubrir el capital circulante (masa salarial) y el financiamiento de largo plazo que proviene de los fondos de inversión que otorga liquidez a los activos no líquidos, las cuales debería destinarse a la realización de los bienes de capital (Graziani, 2003). Hay un financiamiento inicial que proviene de la creación de las deudas por parte de la banca comercial que responde a la demanda las empresas. Éste se canaliza a las familias vía depósitos bancarios (ibid) y se destruye a través de recirculación del gasto y el ahorro de éstos agentes, ${ }^{4}$ que anula la creación de dinero bancario. Este proceso debe estar acompañado por una etapa adicional que debe incluir la recirculación de las ganancias hacia las empresas, vía instituciones financieras no bancarias, que las captan vía emisión de títulos financieros, que realizan a nombre de las empresas. En este análisis se reafirman tres de los supuestos centrales de la teoría heterodoxa: la demanda de dinero determina la oferta, la inversión crea su propio ahorro, y la tasa de interés es una variable monetaria, de carácter distributivo.

En esta visión se reitera que los bancos tienen el monopolio de la creación de las deudas, (denominado como señoriaje por Bossone, 2001), cuya función es crear liquidez para financiar la producción, donde se incluye la producción de bienes y servicios finales y bienes intermedios y de capital, diferenciándose el proceso de realización de la inversión. 5 Ello no implica que a nivel de las empresas individuales, el crédito bancario pueda financiar las diferentes fases del proceso productivo (salarios, bienes intermedios y capital fijo) pero, en el conjunto del sector empresarial, el crédito neto entre las empresas y la banca es igual al valor de la masa salarial, en tanto los créditos utilizados al interior del sector empresarial (para financiar bienes intermedios y de capital) se anulan entre sí, porque los demandantes de bienes capital al solicitar créditos tiene un deber con la banca y los productores de dichos bienes (oferente) tiene un haber, Graziani (2003). Así el crédito neto de la banca es igual a la masa salarial que, al convertirse en ingreso y gasto, recircula hacia la producción vía consumo (demanda de bienes y servicios) y el ahorro, bajo la forma de instrumentos financieros no bancarios.

A partir de lo anterior postulamos que el circuito monetario tiene tres fases (véase Esquema 1). En la primera fase del ciclo 1) se crean deudas bancarias; en la segunda, éstas se destruyen 2) y, en la tercera 3) tiene lugar el proceso de realización de los bienes de capital fijo. Específicamente, en la primera fase del circuito monetario los bancos acomodan las deudas de las empresas solventes por un monto igual a la masa salarial y, aunque pueden cubrir requerimientos de la compra de bienes de capital fijo, este no aparece como deuda neta. El resultado del aumento de la liquidez es la generación de producción (bienes de consumo y de capital) y la creación de ingreso para los factores productivos (salarios y ganancias).

3 Esta discusión se sustenta en la proposición de Graziani, 1998, 2003; y Bossone, 2001, 2003.

4 Siguiendo a Kalecki (Capítulo VII, 1971) se supone que el ahorro de los trabajadores impide la recirculación de la masa salarial hacia las empresas y éstas deben endeudarse para cubrir esta fuga del ingreso.

5 En la mayoría de las explicaciones el financiamiento está relacionado con la inversión, donde destaca la teoría de los fondos prestables (Hick, 1937) y el motivo de financiamiento de Keynes $\left(1937^{\mathrm{a}}, 1937^{\mathrm{b}}\right)$. 
En la segunda fase 2) se genera la conversión de los salarios en ingreso de las familias que destinan al consumo y al ahorro, cuya función es saldar deudas bancarias. Se argumenta que el ingreso de las familias más los intereses por concepto de instrumentos financieros, regresa a las empresas vía consumo. En este esquema el ahorro de las familias bajo la forma de depósitos bancarios es una fuga del circuito monetario (lo cual explica el signo negativo). En esta fase no se realiza la producción de bienes de capital y ni recircula las ganancias hacia la producción (véase Esquema 1).

La tercera fase de este proceso 3) cierra el circuito monetario a partir de la recolección de las ganancias que se transforman en ahorro financiero, por parte de las IFNB que proveen financiamiento de largo plazo para la compra de bienes de capital, o genera liquidez para los activos no líquidos, Toporowski, 2012. Adicionalmente, las ganancias de las empresas pueden ser retenidas por las empresas para financiar los bienes de capital fijo que se compran directamente entre ellas. Este planteamiento fue analizado por Kalecki (capitulo VII, 1971), que postulan que las ganancias generadas por la producción (proveniente del sector de bienes de capital fijo y de consumo capitalista y asalariado) debe regresar a la producción y vaciar el mercados bienes de capital fijo. Es este punto conviene detenerse porque Kalecki introduce los ciclos económicos, explicados a partir de la recirculación parcial de las ganancias a la producción. Adicionalmente las empresas pueden recolectar ganancias del resto de los sectores vía incremento de los precios (y conformar fondos internos y de esa manera financiar la adquisición de bienes de capital fijo (véase Seccareccia, 2003).

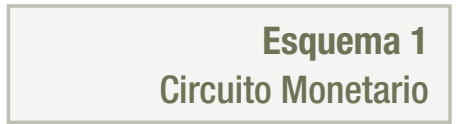

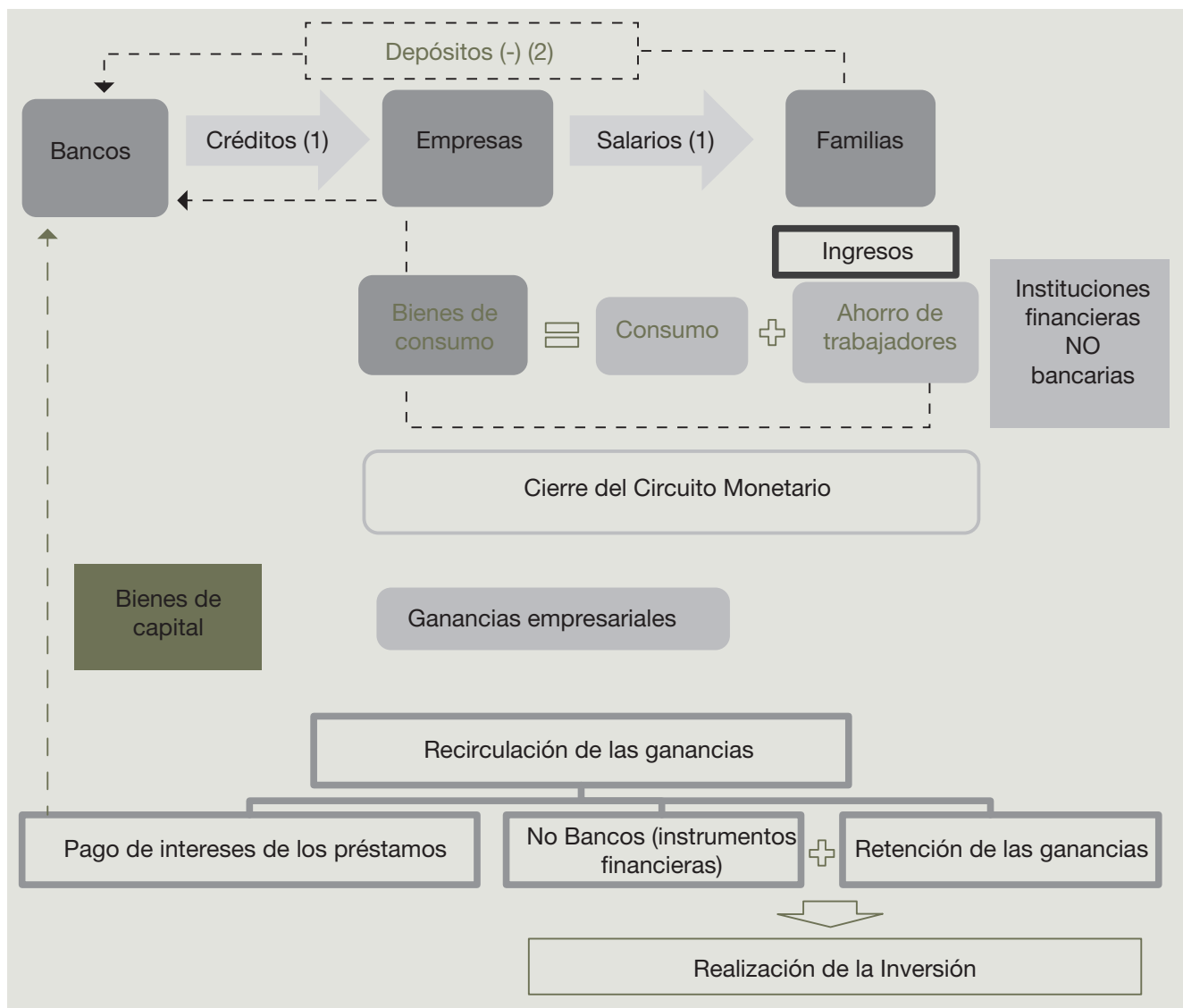


El comportamiento de los diferentes agentes

puede interrumpir el ciclo monetario en sus diferentes fases generando volúmenes de producción por debajo del pleno empleo y desequilibrios en la composición de la producción entre bienes de consuno y de capital fijo
A partir de las diferentes fases del circuito monetario se ubican varias fuentes de inestabilidad. Primero, las empresas acceden a diferentes montos de créditos y sus costos son diferenciados, relajándose el supuesto de liquidez ilimitada, lo cual implica que la banca no sólo determina la solvencia de los agentes, sino que también incide en el volumen y el costo de los préstamos que acomoda, a partir de la fuerza de negociación de los diferentes agentes. Este argumento es central para entender el carácter oligopólico del sistema capitalista, que genera crecimiento económico con diferentes velocidades y reducen la competencia, desarrollando desequilibrios estructurales en países en desarrollo. Específicamente, en este entorno se acelera el crecimiento de las grandes empresas y anula el dinamismo de las empresas pequeñas y medianas (Kalecki capítulo IX, 1971), lo cual, también permite diferenciar el dinamismo de los países productores e importadores de bienes de capital fijo. Segundo, esta diferenciación también permite explicar al acceso diferenciado de las empresas al ahorro del conjunto de la economía, resaltándose que las empresas pequeñas y medianas no tienen acceso a los fondos de inversión (Steindl, 1952). Tercero, el ahorro bajo la forma de depósitos bancarios (depósitos líquidos) aunque puede equilibrar las hojas de balance de la banca comercial, impide que las empresas cancelen sus deudas bancarias, debiendo incrementar sus deudas para anular los créditos iniciales, lo cual provoca creciente pagos de intereses que no recirculan a las empresas, a menos que las ganancias bancarias se transformen en títulos financieros de largo plazo.

Específicamente, el comportamiento de los diferentes agentes pueden interrumpir el ciclo monetario en sus diferentes fases generando volúmenes de producción por debajo del pleno empleo y desequilibrios en la composición de la producción entre bienes de consuno y de capital fijo; creciente endeudamiento por no anular las deudas en cada periodo; $y$ de manera más relevante inducir una recirculación parcial de las ganancias.

En la primera parte del circuito el volumen de la liquidez depende de la preferencia por la liquidez de los bancos, asumiendo éstas instituciones un papel fundamental en el crecimiento económico (Keynes, 1937 b ${ }^{1937^{\circ}}$ Kregel, 1984). En la segunda parte del circuito, las familias pueden generar fugas en el gasto, vía retención del ahorro en depósitos líquidos que impide a las empresas saldar sus créditos bancarios (Graziani, 2003), generando capacidad ociosa no planificada. Finalmente, en la tercera fase del ciclo, las IFNB pueden generar montos insuficientes de financiamiento de largo plazo (Bossone, 2001) o, quizás de manera más relevante puede inducir procesos de sobre-capitalización, (Toporowski, 2012) donde las empresas emiten deudas por encima de sus cuentas por pagar y, por esa vía, accedan a ganancias financieras, elemento no contemplado por el circuito monetario. 6

Adicionalmente, el sistema capitalista puede desestabilizarse por mayores extracciones de rentas del sector empresarial por parte del sector financiero. Altos márgenes financieros bancarios, por altas tasas de interés relacionadas a los préstamos bancarios que pueden neutralizarse vía aumentos de la tasa de interés de los depó-

6 Agradezco este comentario a Riccardo Bellofiore. 
sitos, lo cuales, incrementan el ingreso de las familias y, de esa manera a las empresas. ${ }^{7}$ Por su parte, las IFNB pueden también apoderarse de ganancias extraordinarias cuando existe un poder monopólico en el mercado de capitales, lo cual, empero, puede neutralizarse promoviendo mayor competencia (Bossone, 2003: 156).

\section{El circuito monetario en países en desarrollo: un análisis en la economía mexicana}

Las economías de los países atrasados se han diferenciado de las estructuras económicas de los países desarrollados en dos aspectos clave: primero, la producción doméstica de capital fijo es muy reducida, especialmente en maquinaria y equipo con innovación tecnológica; y, segundo, como resultado de lo anterior, el ahorro doméstico es reducido y se genera una alta dependencia hacia el financiamiento externo. Los antecedentes de esta condición tienen su originen en la inserción de los países atrasados al desarrollo capitalista, que de acuerdo a Rosa Luxemburgo (1913), asumieron la función de realizar la producción de las economías desarrollados (imperialistas), incluido el sector de bienes de capital fijo, 8 combinado con préstamos bancarios e instrumentos financieros no bancarios (mercado de deuda y accionario). ${ }^{9}$ Estos cambios, en su conjunto, modificaron la estructura productiva de los países atrasados, destruyendo su producción autóctona y se especializaron en la exportación de materias primas, acompañadas de crecientes importaciones de bienes producidos de los países desarrollados, incluyendo bienes de consumo, intermedios y de capital. Este periodo se conoció bajo el nombre del "modelo primario exportador".

Con base en dicha tesis, se desarrolló la corriente dependentista, 10 que señalo que los países atrasados no pueden alcanzar un desarrollo autóctono de sus fuerzas productivas, argumentando la ausencia de una burguesía nacional, a partir de lo cual postularon la teoría del subdesarrollo, siendo una de sus expresiones más claras la debilidad de la producción de bienes de capital fijo. De manera alternativa la corriente de pensamiento estructuralista (cepalina) ${ }^{11}$ resaltó que el atraso de la región se explica por la ausencia (o gran debilidad) del sector productor de bienes de capital y la gran dependencia tecnológica combinada con instituciones financieras poco desarrolladas. Con base en lo anterior postularon la teoría de intercambio desigual

7 De acuerdo a Bossone, 2001 el mercado de créditos bancarios no está sujeto a competencia para reducir sus costos por la propia estructura de estas instituciones y la definición de la tasa de interés, mientras el sector financiero bancario si puede beneficiarse por mayores niveles de competencia.

8 La gran limitación de Rosa Luxemburgo fue que supuso el desarrollo tecnológico de los países desarrollados no podía ser realizado en sus países de origen, porque no introdujo el concepto de plusvalía relativa (Palma y Marcel, 1990).

9 El mercado de capitales en los países en desarrollo encuentra sus antecedentes en el siglo XIX. Por ejemplo en México su instalación se ubica en 1895, en Ciudad de México; mientras en Perú, otro país con gran producción mineral, su instalación data de en 1860; y la Bolsa de Comercio de Santiago apareció 1893.

10 Véase Frank, 1967, Marini, 1968, entre otros.

11 Véase, Bielschowsky, 1998, introducción para un análisis de las diversas etapas de la teoría estructuralista. 
(Prebisch, [1949] (1998) y argumentaron que los países desarrollados extrajeron excedentes de los países en desarrollo vía el comercio internacional.

La visión estructuralista dominó en América Latina y los gobiernos organizaron procesos de industrialización sobre la base de la sustitución de importaciones (ISI), con gran intervención pública a través de políticas de promoción industrial y movilización de recursos financieros hacia el sector productivo. Éste proceso, se convirtió en una política económica en la década de los cincuenta del siglo pasado sin lograr desarrollar el sector productor de bienes de capital (proceso trunco, según Fajnzylber, 1983). 12 Gran parte de la formación bruta de capital fue importada, El modelo neoliberal financiada con recursos financieros provenientes del sector público, apostó por el crecimiento vía la banca de desarrollo, fideicomisos y otras instituciones financiede las exportaciones. ras públicas no bancarias, con políticas de tipo de cambio preferen-

En este contexto, se ciales y tasas de interés preferenciales. Este arreglo institucional no desreguló la actividad logró anular las deudas del sector público por el bajo nivel impositivo productiva y financiera y (Mántey, 2000) y generó un endeudamiento creciente en las econoel sector público redujo mías en desarrollo latinoamericanas. Este proceso fue diferente a la su intervención directa industrialización instrumentada en el Sud-este asiático que avanzó en en la economía y en la la constitución del sector de bienes de capital fijo (Amsden, 2003), lo movilización de recursos cual permitió un crecimiento económico más equilibrado.

financieros El modelo neoliberal, instaurado en los países en desarrollo, en las décadas de 1970 y 1970, apostó por el crecimiento de las exportaciones, al traspasar la dinámica del crecimiento al sector privado. En este contexto, se desreguló la actividad productiva y financiera y el sector público redujo su intervención directa en la economía y en la movilización de recursos financieros. Estos cambios fueron acompañados de un proceso de globalización que incrementó la presencia de corporaciones de carácter trasnacional en la actividad económica (Levy, 2015) y abrió el sector financiero a la competencia internacional (Levy y Domínguez, 2016a).

En el modelo de acumulación neoliberal destacan varios elementos, primero, el dominio del sector privado en la actividad productiva, que incluye el gasto de inversión, y continuó con la importación de maquinaria y equipo del resto del mundo, sin fortalecer el sector de bienes de producción doméstico pese a la entrada de las grandes multinacionales (de capital externo y domestico); segundo, la estructura financiera se modificó radicalmente, irrumpiendo instituciones financieras no bancarias, donde resaltan los fondos de pensiones privados, banca de inversión, incluyendo los bancos no bancos (Sofomes, sociedades de objetos múltiples); tercero, dominaron las entidades extranjeras en el conjunto de las instituciones financieras bancarias y no bancarias.

Uno de los resultados de estas modificaciones fue el desarrollo de una organización financiera basada en el mercado de capitales, sin lograr alcanzar el tamaño y la profundidad del mercado de capitales de los centros financieros desarrollados, (véase Levy, 2013). Ello ocurrió en un entorno de instituciones financieras públicas débiles, lo cual implico la movilización de reducidos volúmenes recursos financieros

12 Una interesante discusión sobre las limitaciones del proceso de industrialización se encuentra en Amsden, 2001 y 2004. 
hacía el sector productivo. Adicionalmente, el gasto público en bienes de capital fijo se redujo y dominaron las transferencias, modificándose la composición del gasto público (Levy, 2016b) sin reducir el tamaño del gasto total, generando superávit primarios, en contexto de déficit públicos. Este proceso generó un retroceso del proceso de industrialización en América Latina (Rodrik, 2015) donde México no ha sido la excepción pese a que se dinamizaron las exportaciones de origen manufacturero, sin logar generar superávit en la cuenta comercial ni en la cuenta corriente.

Considerando estas condiciones se discute el despliegue del circuito monetario en México, al revisar la evolución de la formación bruta de capital y los arreglos institucionales de la movilización de liquidez y ganancias en el periodo de financiarización, particularmente las fuentes de financiamiento, donde se destaca que las empresas pequeñas y medianas tuvieron grandes limitaciones en el acceso de la liquidez.

\section{El volumen y la composición del gasto de la inversión productiva en la economía mexicana}

Uno de las particularidades más notorias de la economía mexicana ha sido la relativa estabilidad de la participación del gasto de la inversión productiva en el producto (formación bruta de capital fija, FBKF, con respecto al producto, PIB) a lo largo de los últimos cincuenta años (véase Figura 1a).

Entre 1960-2013, la razón FBKF/PIB alcanzó una media de 19.4\%,13 sin modificaciones drásticas de dicho coeficiente en el periodo de ISI (1960-1982: 19.6\%) con respecto al periodo de regulación (17.1\% entre 1983-1993); y globalización- financiarización (20.6\% entre 1994-2013). Aunque, debe resaltarse, las tasas medias anuales de la FBKF fueron más aceleradas en el periodo ISI (7.5\%), reduciéndose drásticamente en las dos periodos siguiente (4.4 y $3 \%$, respectivamente).

Un segundo aspecto significativo es la dominación del rubro construcción en la FBKF/PIB, (véase Figura 1a). En el periodo ISI, esta variable, alcanzó una participación de casi $18 \%$ con respecto al producto (con una tasa media de crecimiento anual de $7.4 \%$ ), la cual fue reduciéndose a lo largo del periodo, sin perder su dominio (la FBKF de la construcción con respecto al producto en los siguientes dos periodos fue de 15 y $14 \%$ respectivamente, con tasas de medias anuales de crecimiento de 2.2 y $1.8 \%$ ).

Por su parte, las maquinarias y equipo (el otro gran componente de la FBKF) incrementó su participación en el producto de manera moderada (pasó de $4.2 \%$ durante el ISI, a 5.3 y $6.1 \%$ con respecto al producto, en las dos siguientes periodos); con tasas de crecimiento medias anuales de $7.6,7.8$ y $5 \%$, respectivamente, aunque según el origen cambió la composición de este rubro (importado y nacional). En los periodos ISI y de desregulación dominaron las maquinarias y equipo de origen nacional, adquiriendo mayor importancia las de origen importado en el periodo de globalizaciónfinanciarización, como se verá más adelante.

La gran paradoja de la evolución de la FBKF es que durante el periodo de industrialización la demanda por maquinaria y equipos no fue muy distinta al resto del periodo, porque no se logró profundizar el proceso de industrialización, manteniéndose

13 La participación de los coeficientes de los diferentes componentes de la inversión no es igual a 100 , porque esta serie se obtuvo vía la encadenar los índices de precios de las diferentes series. 
vacío el casillero de la innovación tecnológica (Fajnzylber, 1983) explicado por la sustitución de importaciones de bienes finales que no lograron generar encadenamientos completos, que incluyeran los bienes de capital fijo (Amsden, 2004). Empero, en el periodo de financiarización, dirigido por las exportaciones aumentó la participación de bienes de maquinarias y equipo, los cuales, sin embargo, fueron de origen importado, en contextos de cadenas productivas globales que, en México, fortalecieron la presencia de las principales filiales de los países desarrollados, cuya producción se organizó sobre la base de maquila. Ello, como se señaló anteriormente produjo retrocesos en el grado de industrialización de la economía (Rodrik, 2015).

La explicación de esta paradoja se debió a la reducción de la inversión pública que se concentró de manera creciente en la construcción, desapareciendo el gasto público en maquinaria y equipo (véase grafica 1b) (cuyo niveles de participación en el periodo del ISI ascendieron a $2.4 \%$ con relación al producto, cayendo a 0.9 a $0.5 \%$ en la era de desregulación y globalización-financiarización, respectivamente). La FBKF privada con respecto al producto incrementó moderadamente (véase grafica 2) con respecto al producto (promedios con respecto al producto de 13.1, 12.3, y 16.1\%, en los diferentes periodos), dinamizados por los rubros de maquinaria equipo, crecientemente importada.

A partir de lo anterior es posible que, en este último periodo, la FBKF es dinamizada por el gasto privado, con una participación declinante del sector público. La construcción ocupa un papel importante en el gasto de capital fijo del sector público, con una tendencia hacia la baja de las maquinarias y equipos; mientras en el gasto privado se observa un aumento considerable de las maquinarias y equipos, casi todas de origen importado, lo cual, como se verá más adelante tendrá efectos importantes sobre la movilización de la liquidez y la intermediación financiera.

Figura 1a

Comportamiento de la formación bruta de capital fijo con respecto al producto, en porcentajes.

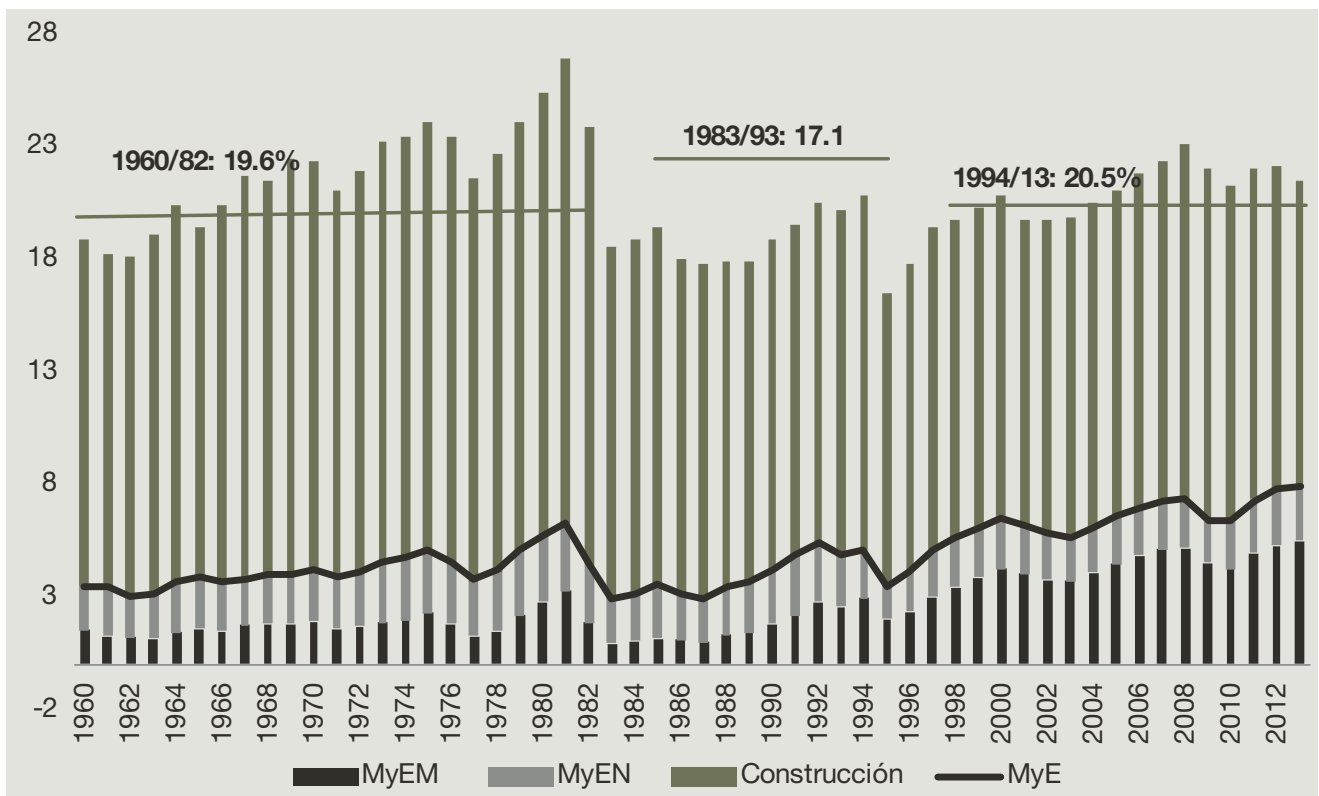

MyE: Maquinaria y equipo; MyEM: Maquinaria y equipo importado, MyEN: maquinaria y equipo nacional. Se calculo vía encadenamiento del índice de precios. Fuente: Elaboración propia con base en información de INEGI. 
Figura 1b

Formación bruta de capital fijo con respecto al produc-

to por origen respecto al producto, en porcentajes

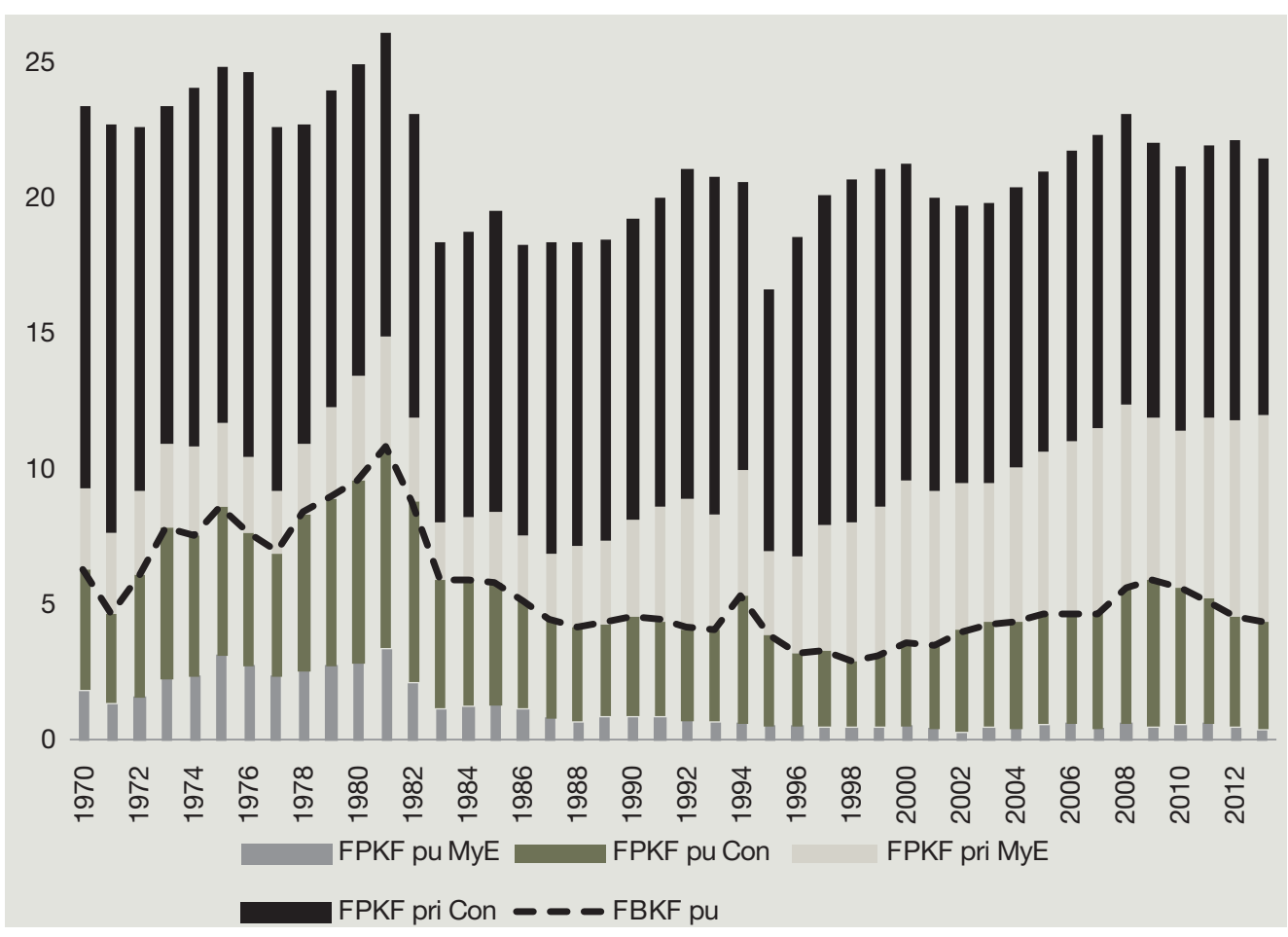

FBKFpu: formación bruta de capital fijo, pública. FBKFPpu MyE: formación bruta de capital fijo en maquinaria y equipo , pública. FBKF pu Con: Formación bruta de capital fijo en construcción, pública. FBKF pri MyE: Formación bruta de fijo en maquinaria y equipo privado, importada. FBKF pri Con: Formación bruta de capital en construcción, privado. Se calculó vía encadenamiento del índice de precios. Fuente: elaboración propia con base en información de INEGI.

\section{Salarios y créditos, financiamiento no bancario e inversión}

En un primer acercamiento encontramos una relación relativamente estrecha entre la participación de los salarios con respecto al producto y la variación del coeficiente de la FBKF/PIB, con excepción del periodo de industrialización donde, donde el Estado asumió un gran activismo en el gasto de capital, especialmente en el la década de 1970, especialmente en el segundo quinquenio (véase Figura 2).

Esta tendencia indicaría que no obstante la producción de bienes de capital se realiza fuera del espacio de producción nacionales es una detonante de la actividad salarial, lo cual explica la relación relativamente estrecha entre el coeficiente de salario/producto y la razón inversión/producto, con excepción del periodo de ISI, donde la fuerza laboral tiene mayor poder de negociación y la banca pública moviliza recursos para financiar la importación de bienes de capital fijos. Por su parte, una proxy de las ganancias (excedente bruto de explotación) muestra reducida relación con el coeficiente de inversión, con base en lo cual se puede inferir que hay una gran fuga de excedentes hacia el mercado internacional, especialmente en el periodo en que las exportaciones adquieren gran relevancia en la composición del producto mexicano. 


\section{Figura 2}

Evolución de los salarios en porcentajes con respecto al producto

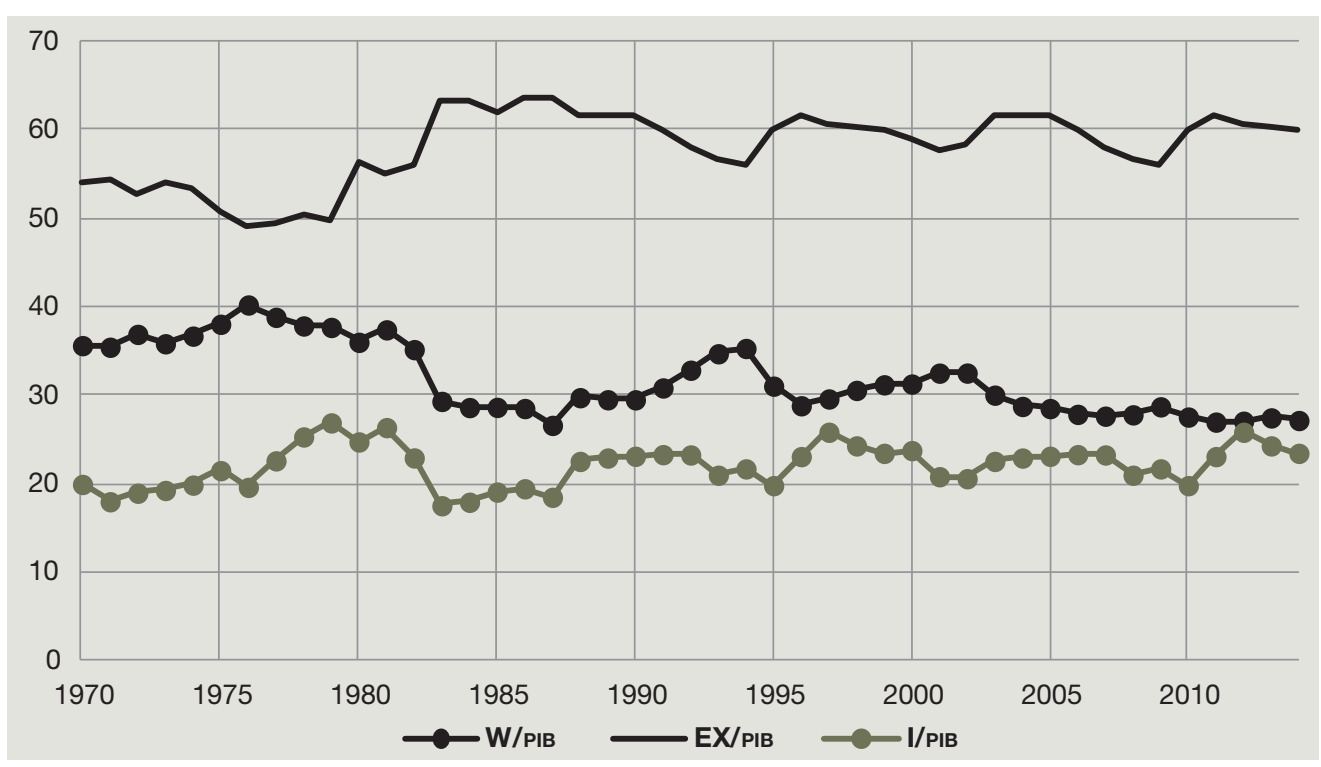

(W), el excedente bruto de operación (EX) y el coeficiente de la inversión (I/PIB).

Fuente: elaboración propia con base en información de INEGI.

La relación entre la variación de los créditos bancarios privados al sector empresarial $^{14}$ y remuneraciones salariales con respecto al producto (véase Figura $3^{a}$ ) es relativamente estrecha, lo cual reafirma los planteamientos avanzados por la teoría del circuito monetario. Específicamente, después de haberse resuelto la crisis bancaria mexicana generada a consecuencia de la crisis de 1994, y haberse realizado la fusión entre la banca nacional con el capital extranjero, se observa una relación estrecha entre la variación de los salarios y los créditos con respecto al producto. Desde 2001 se reanudó la emisión crediticia, observándose una relación relativamente estrecha entre las variaciones de los salarios y los créditos bancarios (con respecto al producto). Desde esta óptica también puede añadirse que el reducido volumen crediticio se debe a salarios reducidos.

También encontramos una relación relativamente estrecha entre el financiamiento no bancario al sector privado y la formación bruta de capital fijo privado (véase Figura 3b). El adelanto de la liquidez para la compra de bienes de capital fijo, el cual, como vimos es preferentemente importado, proviene del financiamiento no bancario, donde destacan "otras fuentes de financiamiento alternativas", compuesto por pasivos no bancarios de empresas que cotizan en la bolsa de valores y emisión de instrumentos de deudas que no cotizan en la bolsa de valores. Otra fuente relevante es el financiamiento externo que reciben las empresas (que en promedio representan más de $70 \%$ del financiamiento no bancario), véase Figura 3b. Un dato adicional es que el volumen de los créditos bancarios no está sincronizados con la formación bruta de capital fijo.

14 Se consideran los créditos al sector empresarial y la vivienda por la dominación del rubro construcción en la formación bruta de capital fija total y privada, no se incluyó el crédito al consumo aunque no modifica las tendencias arriba presentadas. 
Figura 3a

Variaciones de los créditos bancarios y los salarios con respecto al producto, en porcentajes.

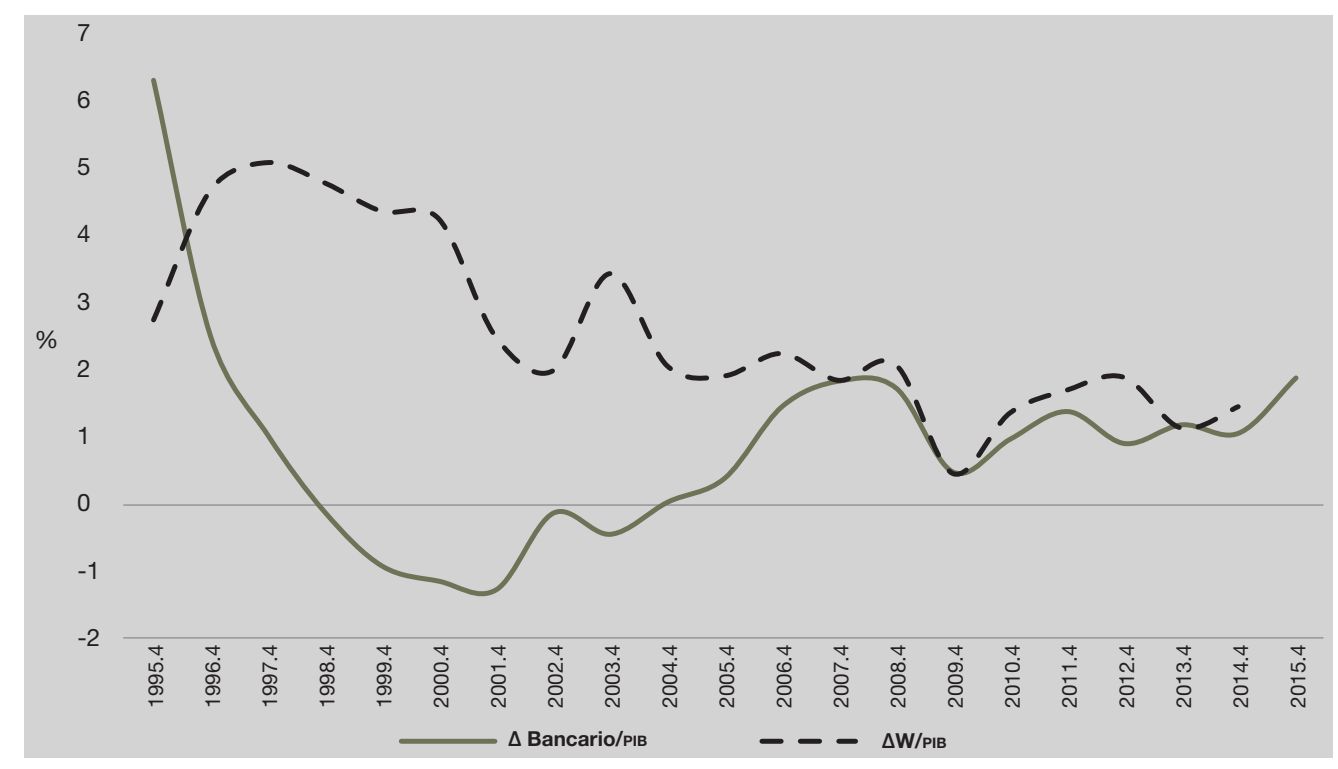

W: salarios; $\Delta$ Bancario/PIB: variación de los créditos bancarios respecto al producto. Fuente: elaboración propia con base en información de Banco de México.

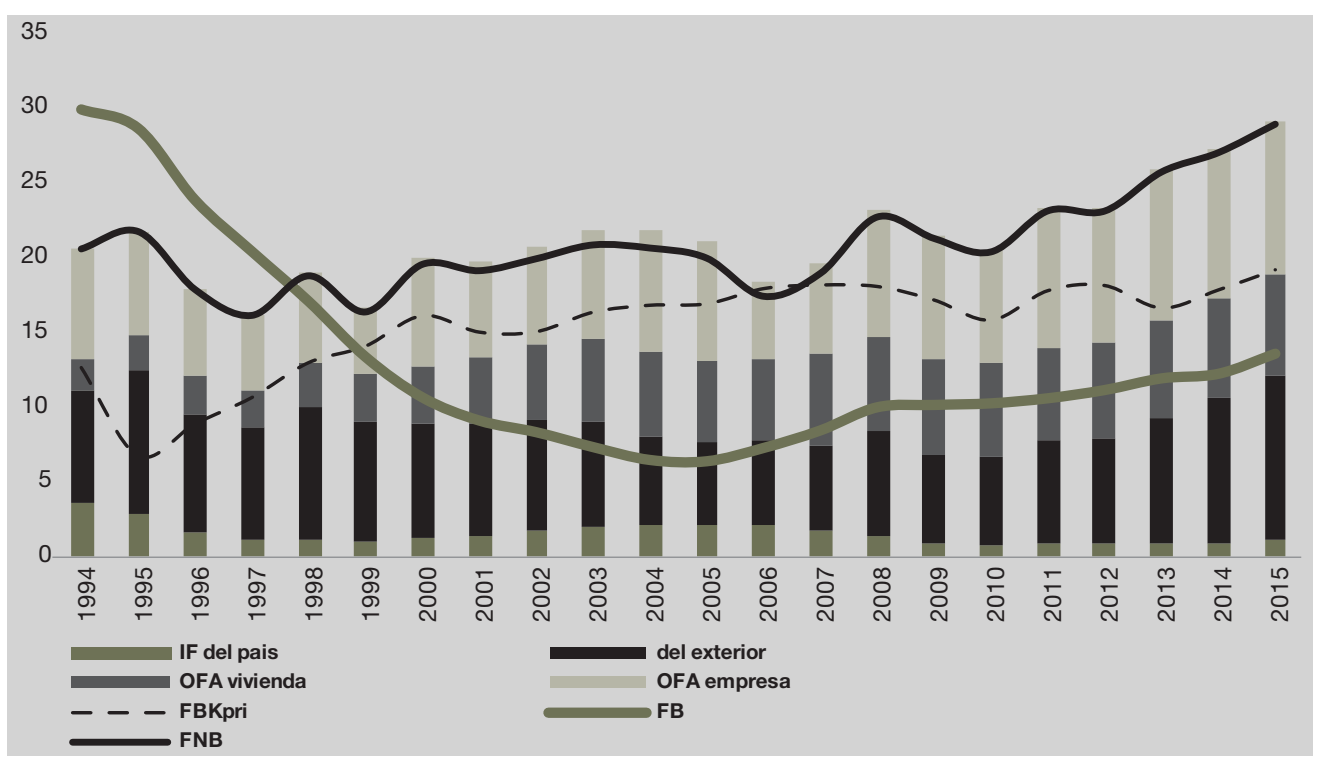

FNB: financiamiento no bancario al sector privado no financiero, FB: financiamiento bancario, FBKpri: Formación bruta de capital fijo privado, IF del país: Intermediarios financieros del país del Exterior; Financiamiento del exterior, OFA vivienda: otras fuentes alternativas de financiamiento relacionados con la vivienda, OFA: otras fuentes de financiamiento alternativas para las empresas. Fuente: elaboración propia con base en información de Banco de México.

A partir de las anteriores estadísticas se puede inferir que las empresas pequeñas y medianas no invierten en activos de capital fijo. Esta aseveración se confirma al examinarse la cuenta financiera del sector no financiero de la economía mexicana (que excluye a la microempresa). Los prestamos (se refiere a los créditos bancarios) no ocupan el primer lugar de financiamiento ni tampoco las otras cuentas por cobrar, 
Figura 4

Cuenta financiera del sector privado no financiero con respecto al producto

teniendo un papel un papel importante los títulos financieros relacionados con acciones y reducidos niveles de seguros y derivados y los valores de deudas, véase Figura 4 , los cuales la pequeña y mediana empresa no tiene acceso. A partir de estas cifras es posible corroborar que las empresas pequeñas y medianas que no pueden emitir acciones ni bonos prácticamente están excluidas del financiamiento a la inversión.

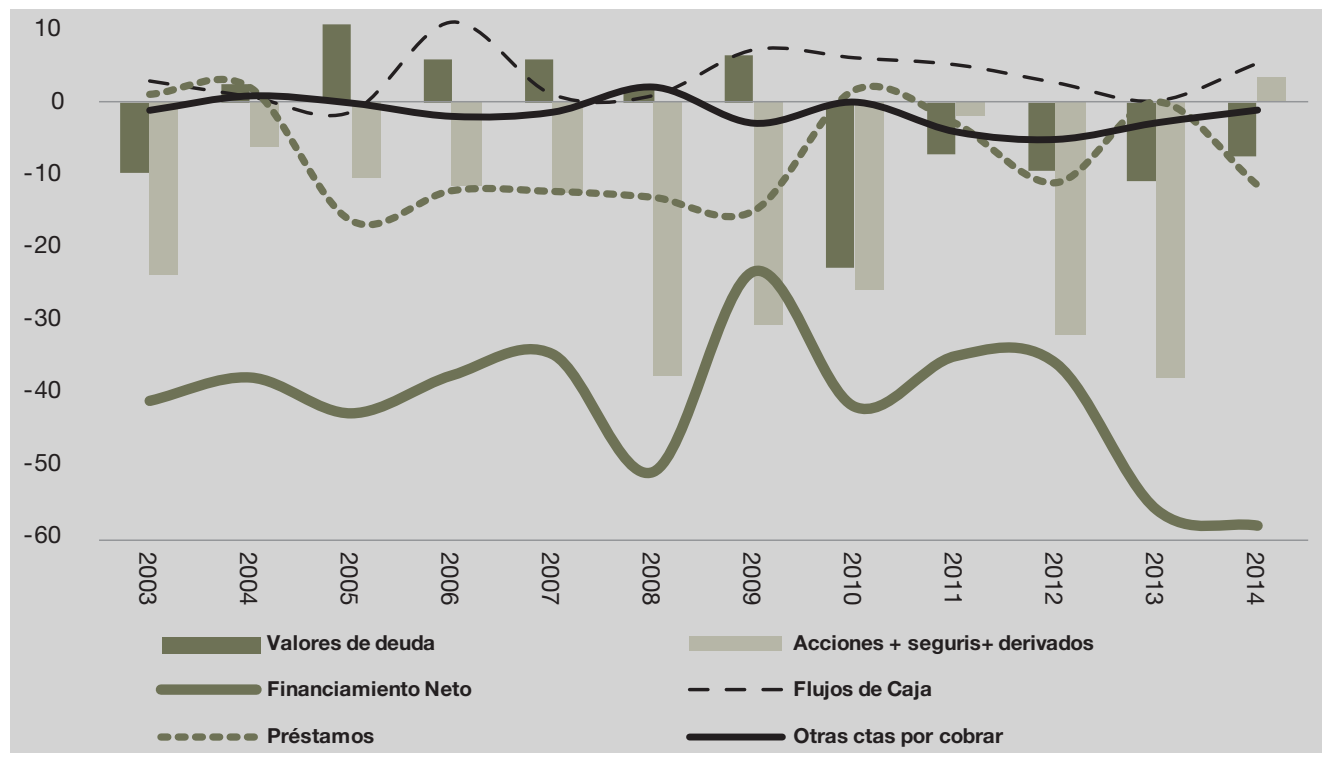

Fuente: elaboración propia con base en información de INEGI, cuenta sectores institucionales.

\section{Profundización financiera y volumen del financiamiento}

ro. La variación de los agregados monetarios $\left(M_{4}\right.$, deducido los agregados monetarios altamente líquidos, $M_{1}$ ) se asemejan a la variación del financiamiento al sector privado no financiero (que incluye la variación de los créditos a las empresas, al consumo y la vivienda), véase Figura 5. Además se destaca que los agregados monetarios son impulsados fundamentalmente por los instrumentos financieros no bancarios, con muy baja participación de los instrumentos no bancarios. Ello evidencia la paradoja de las economías de la región: alta liquidez, impulsada por entrada de capital extranjero y bajo financiamiento al sector productivo.

Una mirada más cercana a las cifras muestran una alta correlación entre la variación del financiamiento bancario al sector privado no financiero con los agregados monetarios bancarios, los cuales, están correlacionados con la captación interna de los bancos residentes (dominados en la economía mexicana por instituciones extranjeras), véase Figura 6a. Entonces, los bancos que operan en la economía mexicana no obstante pertenecer a los grandes corporativos internacionales que diversificaron sus activos desplegando innovaciones financieras para diversificar sus ingresos, han 


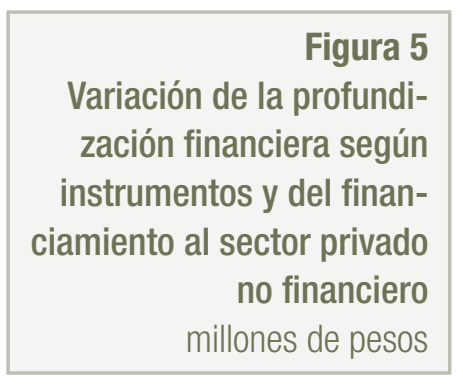

seguido una estrategia diferente. Se han concentrada en la emisión de créditos, cubriendo el capital circulante, como se discutió anteriormente.

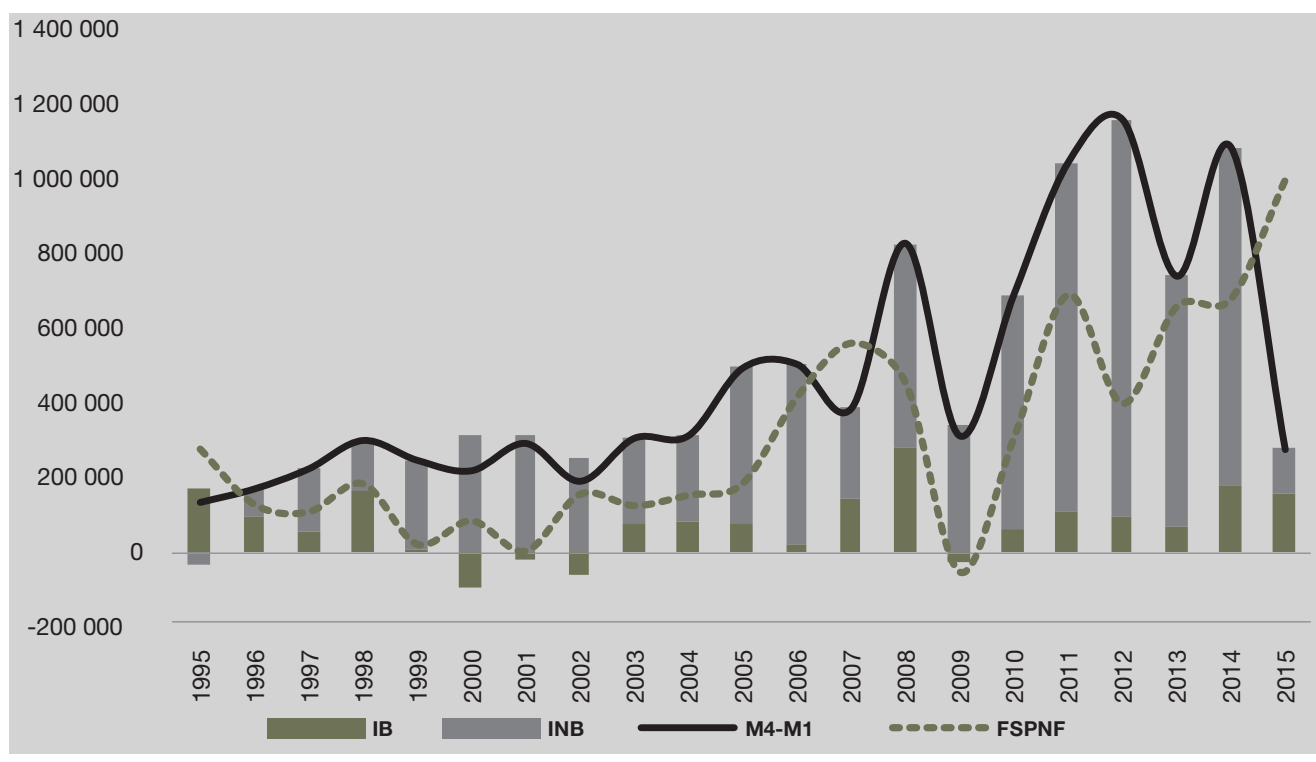

M4: variación de los agregados monetarios amplios, M1: variación del os agregados monetarios totalmente liquidos, INB: Agregados monetarios monetarios de instrumentos no bancarios, IB: Agregados monetarios de instrumentos bancarios Fuente: elaboración propia con base en Banco de México.

Las relaciones se modifican cuando se analizan la correlación de la variación del financiamiento no bancario al sector privado no financiero y la variación de los agregados monetarios no bancarios, véase Figura $6^{\mathrm{b}}$. Primero el movimiento de las variables es relativamente independientemente, mucho mayor la variación de los agregados monetarios no bancarios que el financiamiento no bancario hacia el sector no financiero, impulsado por los flujos de los valores públicos de los residentes, seguido por valores públicos negociados con no residentes (inversión extranjera), ahorro forzado en poder de las sociedades de inversión relacionadas con las pensiones (Siefores), y bonos privados. Lo anterior indica que la profundización financiera no estuvo muy relacionada a la ampliación del capital productivo en la economía mexicana, en el periodo analizado. 
Figura 6a

Variación de los agregados monetarios de origen

bancario y variación de financiamiento bancario al sector privado no financiero, millones de pesos

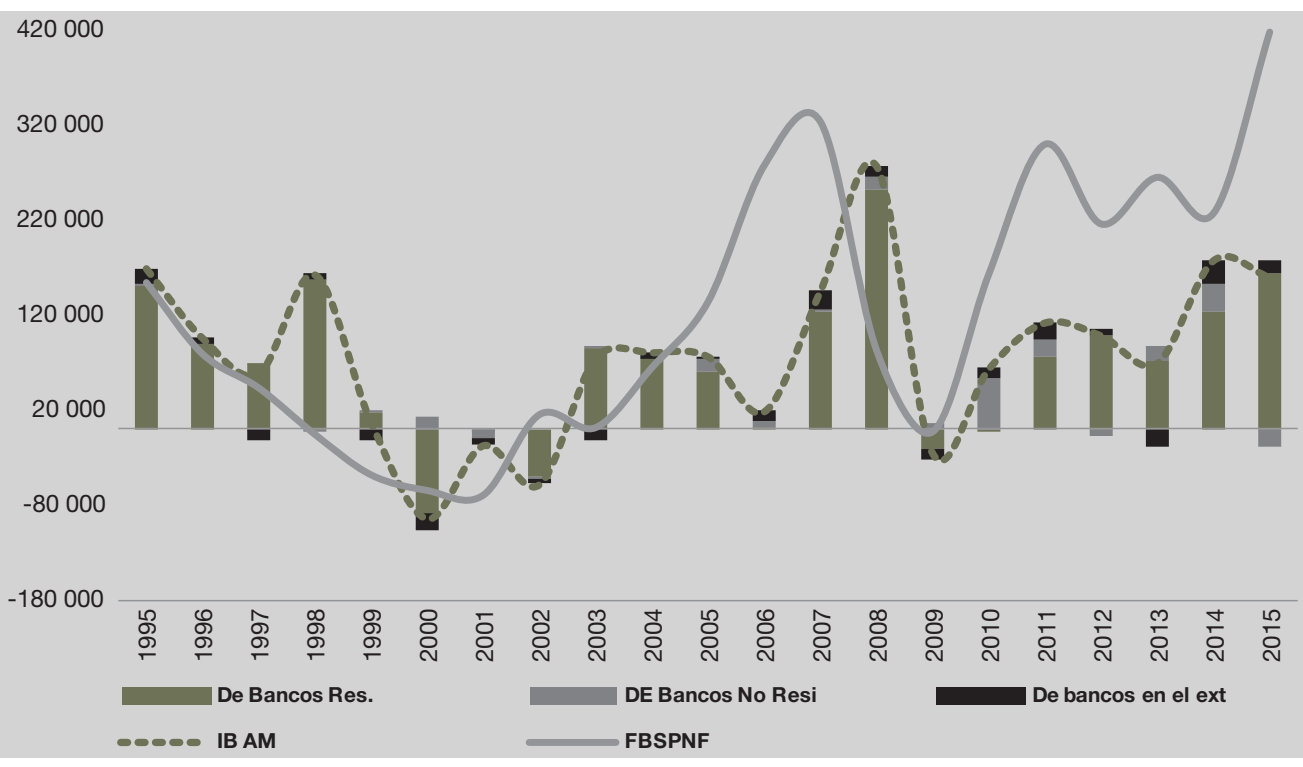

FBSPNF: variación del financiamiento bancario del sector privado no financiero, IB AM. Variación de los instrumentos bancarios de los agregados monetarios. Fuente: elaboración propia con base en información de Banco de México.

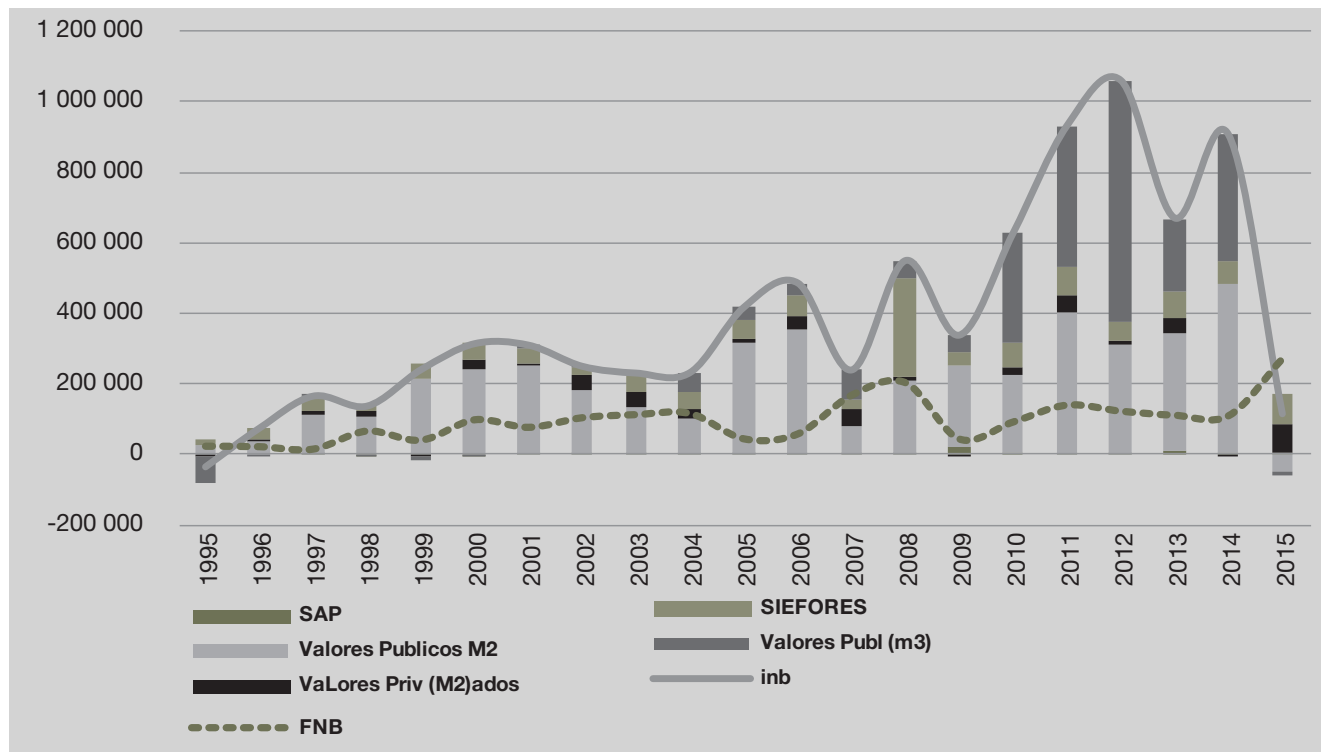

SAP: Sociedades de ahorro y prestamos; inb: instrumentos no bancarios; FNB: financiamiento no bancario. Fuente: elaboración propia con base en información de Banco de México.

Conclusiones

La teoría del circuito monetario es un instrumento válido para discutir la circulación de los flujos financieros en las economías capitalistas desarrolladas y atrasadas. Involucra la relación entre empresas, bancos y familias en el proceso de creación de deudas, generación de riqueza y cancelación de deudas, sin obviar la recirculación de las ganancias que provee la liquidez para realizar los activos de fijos. 
En esta discusión se combinan las propuestas de los circuitistas y Kalecki, donde los primeros resaltan la capacidad de los bancos en crear dinero que definen como estructuralmente no neutro y endógeno, lo cual implica que está ligado a la producción y apertura los ciclos productivos, por consiguiente la preferencia por la liquidez de los bancos determina el ritmo de la producción, la composición y permite explicar los diferentes ritmos de crecimiento de las grandes empresas corporaciones y las pequeñas y medianas empresas. La versión italiana del circuito monetario (Graziani, Bossone) advierte que los créditos bancarios neto financian el capital circulante, específicamente la masa salarial, lo cual implica que el financiamiento de la inversión se relaciona con las ganancias generadas por la producción, las cuales son retenidas directamente por las empresas o canalizadas hacia el mercados financieros no bancarias, reforzando el planteamiento que la producción (donde se incluyen los bienes de capital fijo crean su propio financiamiento vía el ahorro) genera su propio ahorro y, por consiguiente su propio financiamiento. Kalecki advierte que la recirculación de las ganancias puede generar ciclos económicos en tanto recircula parcialmente a la producción y puedes ser sujeta a generar ganancias financieras y puede generar procesos de sobre-capitalización que pueden inducir a crisis del sistema capitalista.

Los países atrasados se distinguen por tener un débil sector de producción de bienes de capitales, dependientes de la importación de maquinarias y equipo. Ello provoca la generación de bajos volúmenes de ahorro y debilidad de instituciones financieras no bancarias. Estos vacíos se han resuelto a través de la movilización pública de recursos financieros para financiar los bienes de capital y políticas de industrialización destinados a fortalecer el sector de bienes de capital. Ello se modificó en el periodo de globalización liderado por el capital financiero (financiarización), asumiendo el sector privado vía mecanismos de mercado el financiamiento de la inversión, no accesibles a la pequeña y mediana empresa, generando un proceso de concentración y centralización de la actividad económica.

América Latina y, particularmente México, los bienes de producción en el periodo de financiarización son realizados fundamentalmente por el sector privado, y no se producen en los espacios domésticos, manteniendo su carácter de importado. Los créditos bancarios están relacionados con los salarios y los instrumentos financieros no bancarias están ligados con el gasto de la inversión. Finalmente, la profundización financiera amplia la intermediación financiera sin lograr incrementar el financiamiento al sector productivo no financiero.

\section{Referencias}

Amsden, A. (2001[2004]). The rise of the "The Rest". Challenges to the West from Late-industrialization economies, New York, US, pp. Oxford University Paperback.

AMSDEN, Alice (2004). "La sustitución de importaciones en las industria de alta tecnología. Prebisch renace en Asia", Revista CEPAL, 82, Abril, pp. 75-90.

BellofiORE, Riccardo y Mario SECCARECCIA (1999). 'Monetary circuit' in P.A. O'HARA (editors) Encyclopedia of Political Economy (II), London and New York pp. Routledge, Vol II, pp. 753-756. 
BIELSCHOWSKY, Ricardo (1998). "Cincuenta años del pensamiento de la CEPAL. Una reseña", Cincuenta años de pensamiento en la Cepal. Textos Seleccionados, R. BIELSCHOWSKY (editor), Fondo de Cultura Económica, CEPAL, México, 1998, pp. 9-62

Bossone, Biaggio (2001). "Circuit theory of banking and finance", Journal of banking and finance 25, pp. 857-890.

Bossone, Biaggio (2003). "Thinking of the Economy as a circuit", Modern Theories of Money, Louis Philippe Rochon y Sergio Rossi (editors). Edward Elgar, pp. 142-172.

FAJNZYLBER, Fernando [1983] (1998). "La industrialización trunca de América Latina" reproducida en Cincuenta años de pensamiento en la CEPAL(II), Ricardo Bielschowsky (editor), Santiago, Chile pp. Fondo de Cultura Económica, pp. 817-852.

FRANK, Andre Gunder (1967). Capitalism and Underdevelopment in Latin America pp. Historical Studies of Chile and Brazil. New York: Monthly Review Press.

GraZIANI, Augusto (2003). The monetary theory production, Cambridge University Press, UK.

GrazIANI, Augusto (1989). "The Theory of the Monetary Circuit" Thames paper in Political Economy, North East London Polytechnic, London UK, pp. 1-25.

GraZianI, Augusto (1984). "The debate on Keynes's finance motive”, Economic Notes, Vol. 13(1) Siena.

HICK, John (1937). "Mr. Keynes and the Classics. A Suggested Interpretation”, Econometrica, Vol. 5 (2) (Abril): 147-15, http://www.jstor.org/stable/1907242, acceso: 03/05/2011.

KALDOR, Nicholas (1959). "Problemas Económicos de Chile", en Trimestre Económico, Vol. 26, 102(2), abriljunio, Fondo de Cultura Económica, México, pp. 170-221.

KALECKI, Michal [1937/1957] 01977. "El capital de la empresa y la inversión" en Ensayos Escogidos sobre la Dinámica de la Economía Capitalista, Fondo de cultura Económica, México, pp. 123-127.

KALECKI, Michal [1933/1954] (1977). "Los determinantes de las ganancias" en Ensayos Escogidos sobre la Dinámica de la Economía Capitalista, Fondo de cultura Económica, México, pp. 94-109.

KEYNES John Maynard [1936] (1964). "The general theory of employment, interest, and money", Harvest/ Harcourt, Inc.

KEYNES John Maynard [1937a] (1973). "The General theory of employment”, reprinted in The Collected Writings of John Maynard Keynes, Vol XIV, D. Moggridge (editor). Macmillan, London, pp. 109-124.

KEYNES J.M. [1937b] (1973), "Alternative theories of the rate of interest", reproducidos en The Collected Writings of John Maynard Keynes, Vol XIV, D. Moggridge (editor), Macmillan, London: 201 -214.

KEYNES, John Maynard [1937c] (1973). “The 'Ex Ante' theory of the rate interest), reproducidos en The Collected Writings of John Maynard Keynes, Vol XIV, D. Moggridge (editor). Macmillan, London, pp. 215-223.

KREGEL, Jan (1984). "Constrains on the expansion of output and employment: real or monetary?”, Journal of Posy Keynesian Economics, Vol. VII (2), pp. 139-152.

LEVY, Noemi y Christian DomingueZ (2016a). "The operation of the Mexican banking system under foreign multinational corporations' control: new activities and traditional income, International Review of Applied Economics, Vol. 30(4).

LEVY, Noemi. (2016b). "Política fiscal y desequilibrios económicos: el impacto de la composición del gasto público sobre el crecimiento de la economía mexicana" economíaunam, 39, septiembre-diciembre, pp. 82-1045.

LEVY, Noemi (2015). "The transformation of developing economies in the process of financialization: a discussion of the growth constrains based on the Mexican economy", ponencia presentada la PostKeynesian Grenoble Conference, Grenoble (France), 10-12 diciembre, 2015. 
LEVY, Noemi (2013). Dinero, estructuras financieras y financiarización: un debate teórico institucional, Itaca,

Facultad de Economía, UnAM, México.

LUXEMBURG Rosa (1913). "International Loans" in The accumulation of Capital, http, pp.//www.marxists.org/ archive/luxemburg/1913/accumulation-capital/index.htm

MARINI, Ruy Mauro (1968). 'Subdesarrollo y revolución en América Latina', Tricontinental, N.7, La Habana, Cuba en http://www.marini-escritos.unam.mx/349_subdesarrollo_revolucion. html, fecha de acceso, 27/III/ 2013.

MÁNTEY, María Guadalupe (2000). "Políticas financieras para el desarrollo en México: ¿Qué hemos aprendido de 1958 a 2008?, Cincuenta años de políticas financieras para el desarrollo en México (1958-2008), María Guadalupe Mántey y Noemi Levy (editoras), Plaza y Váldes, UNAM, México, pp. 15-44.

MOORE, Basil (1988). "Horizontalists and Verticalists: The Macroeconomics of Credit Money". Cambridge, University Press.

PALMA, Gabriel y Mario MARCEL (1990). "Kaldor y el discreto encanto de la burguesía chilena" Colección de Estudios de la CIEPLAN, No. 28, Junio, pp. 85-120.

PARGUEZ, Allain y Mario SECCARECCIA (2000). "The credit theory of Money: the monetary circuit approach", in John Smithin (ed.) What is money? Canada and the USA: Routledge, pp. 101-123.

PREBISCH, Raúl [1949] (1998). "El desarrollo económico en América Latina y algunos de sus principales problemas", Cincuenta años pensamiento en la CEPAL, Texto seleccionados, Ricardo Bielschowsky (editor), FCE-CEPAL, 69-129.

ROCHON, Louis Philippe (2001). "Horizontalism: setting the record straight" in Louis Philippe ROCHON and Matias VernANGo (editor) Credit, interest rate and open economy. Essays in Horizontalims, Chelten1ham: Edward Elgar.

ROCHON, Louis Philippe y Sergio Rossı (2004). "Central bank in the monetary circuit" in Central Banking in the Modern World. Alternatives Perspectives, Lavoie MARC y Mario SECCARECCIA (editores). Edward ELGAR, pp. 144-163.

ROCHON, Louis Philippe (2005). "The existence of monetary profits within the Monetary circuit" in The monetary theory of production. Tradition and Perspectives, Giuseppe FONTANA and Riccardo REALFONSO (editores), Palgrave, Macmillan, New York, pp. 125-138.

ROCHON, Louis Philippe (2006). "Endogenous money, central banks and the banking system: Basil Moore and the supply of credits", in Complexity, Endogenous Money and Macroeconomic Theory, Essays in Honour of Basil Moore, Marc Setterfield, editor, Edward Elgar. Cheltenham, UK, pp. 170-186.

RODRIK, Dani (2015). Premature Deindustrialization, NBER Working Paper No. 20935, febrero 2015, NBER

Program(s): DEV EFG ITI PR, http://www.nber.org/papers/w20935, acceso 20 octubre, 2016.

STEINDL, Joseph (1952). "Maturity and stagnation in American Capitalism, Monthly Review, 1976.

SECCARECCIA, Mario (2003). "Pricing, Investment and the Financing of Production within the Framework of the Monetary Circuit: Some Preliminary Evidence", Modern Theories of Money, Louis Philippe RocHON y Sergio Rossı (editors). Edward ELGAR, pp. 173-197.

SECCARECCIA, Mario (2012/2013). "Financialization and the Transformation of Commercial Banking: Understanding the Recent Canadian Experience before and during the International Financial Crisis." Journal of Post Keynesian Economics, 35(2), pp. 277-300.

TOPOROWSKI, Jan (2012), "Overcapitalization” en Handbook of Critical Issues in Finance , Jan TOPOROWSKI y Jo MICHELL (editores). Edward ELGAR Publishing Limited, Cheltenham, UK, Northampton USA, pp. 270-273. 